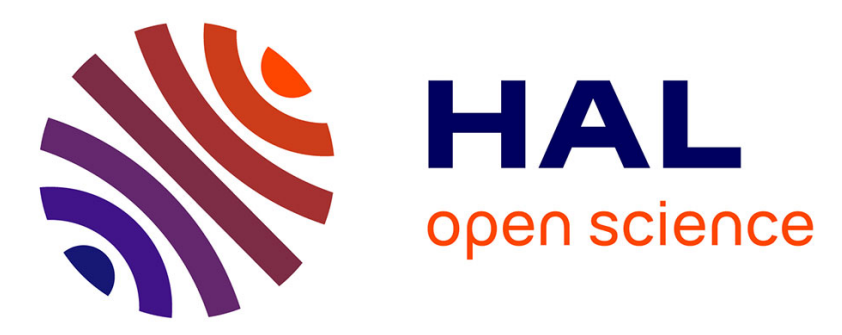

\title{
Modeling of point defects and rare gas incorporation in uranium mono-carbide
}

\author{
A. Chartier, L. van Brutzel
}

\section{To cite this version:}

A. Chartier, L. van Brutzel. Modeling of point defects and rare gas incorporation in uranium monocarbide. Nuclear Instruments and Methods in Physics Research Section B: Beam Interactions with Materials and Atoms, 2007, 255 (1), pp.146-150. 10.1016/j.nimb.2006.11.017 . cea-02513468

\section{HAL Id: cea-02513468 https://hal-cea.archives-ouvertes.fr/cea-02513468}

Submitted on 20 Mar 2020

HAL is a multi-disciplinary open access archive for the deposit and dissemination of scientific research documents, whether they are published or not. The documents may come from teaching and research institutions in France or abroad, or from public or private research centers.
L'archive ouverte pluridisciplinaire HAL, est destinée au dépôt et à la diffusion de documents scientifiques de niveau recherche, publiés ou non, émanant des établissements d'enseignement et de recherche français ou étrangers, des laboratoires publics ou privés. 


\title{
Modeling of point defects and rare gas incorporation in uranium mono-carbide
}

\author{
A. Chartier ${ }^{\mathrm{a}, *}$, L. Van Brutzel ${ }^{\mathrm{b}}$ \\ ${ }^{a}$ CEA-Saclay, DEN/DPC/SCP/LM2T bât. 450 Sud, 91191 Gif-Sur-Yvette, France \\ ${ }^{\mathrm{b}}$ CEA-Marcoule, DEN/DTCD/SECM/LCLT, 30207 Bagnols-Sur-Cèze, France
}

\begin{abstract}
An embedded atom method (EAM) potential has been established for uranium mono-carbide. This EAM potential was fitted on structural properties of metallic uranium and uranium mono-carbide. The formation energies of point defects, as well as activation energies for self migration, have been evaluated in order to cross-check the suitability of the potential. Assuming that the carbon vacancies are the main defects in uranium mono-carbide compounds, the migration paths and energies are consistent with experimental data selected by Catlow[C.R.A. Catlow, J. Nucl. Mater. 60 (1976) 151]. The insertion and migration energies for He, Kr and Xe have also been evaluated with available inter-atomic potentials [H.H. Andersen, P. Sigmund, Nucl. Instr. and Meth. B 38 (1965) 238]. Results show that the most stable defect configuration for rare gases is within uranium vacancies. The migration energy of an interstitial $\mathrm{Xe}$ is $0.5 \mathrm{eV}$, in agreement with the experimental value of $0.5 \mathrm{eV}[\mathrm{Hj}$. Matzke, Science of advanced LMFBR fuels, Solid State Physics, Chemistry and Technology of Carbides, Nitrides and Carbonitrides of Uranium and Plutonium, North-Holland, 1986].
\end{abstract}

Keywords: Uranium carbide; EAM potential; Molecular dynamics; Point defects; Migration; Rare gases

\section{Introduction}

Uranium mono-carbide is envisioned as a potential fuel for VHTR (very high temperature reactor) as well as for GFR (gas fast reactor) nuclear power plants. Numerous physical properties have been measured in UC [3], including uranium and carbon self diffusion coefficients. But, the knowledge of its behaviours under radiation (including radiation resistance and rare gas induced swelling) is essentially based on analogies with $\mathrm{UO}_{2}$. In order to tackle those behaviours, a new EAM potential is established for uranium mono-carbide.

First, the parameters entering this EAM potential were fitted to the structural properties of metallic uranium and uranium mono-carbide. Cell parameters, bulk modulus,

\footnotetext{
* Corresponding author. Tel.: +3316908 3168; fax: 33169089221.

E-mail address: achartier@carnac.cea.fr (A. Chartier).
}

and cohesive energies have been used as fitting parameters. The formation energies of point defects as well as activation energies for self migrations are examined to crosscheck the suitability of the potential. The reaction of rare gas atoms ( $\mathrm{He}, \mathrm{Kr}$ or $\mathrm{Xe}$ ) embedded in the uranium mono-carbide compound is modelled with well known interatomic potentials [2]

\section{Uranium carbides}

The structure of stoichiometric uranium mono-carbide is rock-salt (B1, space group 225). For high temperature $\left(>1400{ }^{\circ} \mathrm{C}\right)$ [4], the phase field is enlarged, and hence underand over-stoichiometric UC may be stable. For $\mathrm{UC}_{1+x}$ $(x>0)$ the over-stoichiometric carbon is simply stabilized by substituting a single carbon, with two carbons. It forms then a $\mathrm{C}-\mathrm{C}$ dimmer, which is comparable to the one that appears in the uranium di-carbide $\mathrm{UC}_{2}$. 
The electronic structure of the uranium carbides are rather complex [3]. Following the general rules of Hill [5], uranium compounds, where $\mathrm{U}-\mathrm{U}$ distance is less than $3.54 \AA$, exhibit metallic electronic structure due to the overlaps of f-orbitals. This rule applies to uranium monocarbide, where the U-U distance is $3.50 \AA$, as shown by experimental measurements as well as ab initio calculations $[6,7]$. For over-stoichiometric uranium carbides, the metallic character does persist and the $\mathrm{C}-\mathrm{C}$ bonds are covalent [8], like in graphite.

\section{Fitting empirical potentials}

Experimental details on the electronic structure described above lead to the choice of EAM potentials for describing the $\mathrm{U}-\mathrm{U}$ and $\mathrm{U}-\mathrm{C}$ bonds for $\mathrm{UC}$. Different forms of potentials have been tested for $n$ and $m$ (see equation below) varying from 0 to 2 for the electron density term, and the present one $(n=m=2)$ is found to be the most suitable for the fit. No directional interaction has been included in the potential as the present parameter set of the potential is enough for UC description. These potentials are composed of two terms: one repulsive twobody term Buckingham-like form:

$\Phi\left(r_{i j}\right)=A_{i j} \exp \left(-\frac{r_{i j}}{\rho_{i j}}\right)$,

and a N-body potential with the second moment approximation, defined as follow:

$F\left(\rho_{i}\right)=\sqrt{\rho_{i}} \quad$ with $\rho_{i}=\sum_{i \neq j} A_{i} r_{i j}^{n} \exp \left(-B_{i}\left(r_{i j}-r_{0}\right)^{m}\right)$,

where in both cases, $r_{i j}$ is the distance between atoms $i$ and $j$, the other parameters being adjustable, and $n=m=2$

The $\mathrm{C}-\mathrm{C}$ bonds are described using a simple StillingerWeber potential that was recently shown [9] to describe properly the carbon bonds in diamond. It was chosen preferentially to the Tersoff potential as it includes fewer parameters for fitting: only very few data (carbon Frenkel pair formation energy and activation energy for migration) are available for the fit.

$\left.\Phi\left(r_{i j}\right)=A_{i j} \exp \left(\frac{\rho_{i j}}{r_{i j}-r_{\max }}\right) \frac{B_{i j}}{r_{i j}^{4}}-1\right)$.

The fitting of the parameters of the potentials was performed using a least-squares method (implemented in the GULP code [10] we used) for minimizing the difference between chosen experimental physical properties and calculated ones. The parameters were fitted upon the bcc phase of metallic uranium $(\gamma-\mathrm{U})$ in order to insure a relevant description of the $\mathrm{U}-\mathrm{U}$ metallic electronic structure. The U-C interaction parameters were fitted upon the B1, $\mathrm{B} 2$ and $\mathrm{B} 3$ phases of uranium mono-carbide. Yielding a precise description of different coordination states since uranium does have 6 carbon first neighbours in the B1 structure, eight in the B2 structure and only four in the B3 structure.

The fitted parameters have been reported on Table 1, the calculated physical properties using this potential have been reported on Table 2, and compared with experimental data. The physical properties on which the fit has been performed are indicated in italic. The other properties have been calculated to assess the empirical potentials. Table 2 shows that the present potential reproduces the main properties of UC in its B1 structure. The heat capacity at constant volume for $300 \mathrm{~K}$ has been calculated using the phonon spectra only. Nevertheless, the calculated value $(42.70 \mathrm{~J} / \mathrm{mol} \mathrm{K})$, compares closely to the experimental value $(49.95 \mathrm{~J} / \mathrm{mol} \mathrm{K})$, when the electronic part $(5.53 \mathrm{~J}$ $/ \mathrm{mol} \mathrm{K}$ ) [11] is added. The energy differences between the

Table 1

Empirical potentials parameters fitted to reproduce the physical properties of uranium mono-carbide

\begin{tabular}{lclll}
\hline Buckingham & $A(\mathrm{eV})$ & $\rho(\AA)$ & & Cutoff $(\AA)$ \\
\hline U-U & 668.546808 & 0.408333 & - & 12.0 \\
U-C & 30.885011 & 0.814952 & - & 12.0 \\
Stillinger-Weber & & & $B\left(\AA^{4}\right)$ & $r_{\max }(\AA)$ \\
\hline C-C & 1.10000 & 1.368 & 2.078 & 2.5257 \\
EAM & $A\left(\AA^{-2}\right)$ & $B\left(\AA^{-2}\right)$ & $r_{0}(\AA)$ & Cutoff $(\AA)$ \\
\hline U & 1.301894 & 0.668659 & 1.862363 & 6.5 \\
C & 33.446287 & 1.318078 & 1.512686 & 5.5 \\
\hline
\end{tabular}

The $A$ value of the Stillinger-Weber parameter published by Barnard [9] for $\mathrm{C}-\mathrm{C}$ interactions $(19.1 \mathrm{eV})$ has been adjusted in order to reproduce carbon Frenkel pair formation energy and carbon interstitial migration.

Table 2

Comparison between calculated properties using the EAM potential (see Table 1 for parameters) and the corresponding experimental values

\begin{tabular}{llll}
\hline $\mathrm{UC}(\mathrm{B} 1)$ & EAM & Exp. & Ref. \\
\hline Volume $\left(\AA^{3}\right)$ & 121.46 & 122.07 & {$[18]$} \\
$B(\mathrm{GPa})$ & 176 & 157.5 & {$[19]$} \\
$C_{11}(\mathrm{GPa})$ & 322 & 315 & {$[19]$} \\
$C_{12}(\mathrm{GPa})$ & 104 & 79 & {$[19]$} \\
$C_{44}(\mathrm{GPa})$ & 39 & 65 & {$[19]$} \\
$\mathrm{C}_{\mathrm{V} 300 \mathrm{~K}}(\mathrm{~J} / \mathrm{mol} \mathrm{K})$ & 42.70 & 49.95 & {$[11]$} \\
$S_{300 \mathrm{~K}}\left(\mathrm{~J} / \mathrm{mol} \mathrm{K}^{-1}\right.$ & 59.2 & 59.6 & {$[20]$} \\
$\mathrm{LO}(\Gamma)\left(\mathrm{cm}^{-1}\right)$ & 402 & 400 & {$[9]$} \\
$\alpha\left(10^{-5} \mathrm{~K}^{-1}\right)$ & 0.74 & 1.004 & {$[15]$} \\
$E_{\text {cohh }}(\mathrm{UC}-\mathrm{B} 1)(\mathrm{eV})$ & -14.34 & -14.55 & {$[21]$} \\
$E(\mathrm{~B} 2)-\mathrm{E}(\mathrm{B} 1)(\mathrm{eV})$ & 0.43 & 0.5 & Ab initio \\
$E(\mathrm{~B} 3)-\mathrm{E}(\mathrm{B} 1)(\mathrm{eV})$ & 0.61 & 0.7 & Ab initio \\
$\gamma-\mathrm{U}$ & & & \\
$a(\AA)$ & 3.539 & 3.532 & {$[22]$} \\
$B(\mathrm{GPa})$ & 123 & 116 & {$[17]$} \\
$E_{\text {coh }}(\mathrm{U})(\mathrm{eV})$ & -5.42 & -5.4 & {$[22]$} \\
\hline
\end{tabular}

Values in italic have been used in the fitting procedure. Note that the heat capacity at constant volume has been evaluated using the phonon spectra. Adding the electronic contribution $C_{\text {Velectronic }}$ of $5.53 \mathrm{~J} / \mathrm{mol} \mathrm{K}$ at $300 \mathrm{~K}$ [11], the calculated heat capacity is very close to the experimental value. 
$\mathrm{B} 1$ and B2/B3 structures are also close to the values obtained using ab initio calculations [12].

The parameter $\mathrm{A}$ of the $\mathrm{C}-\mathrm{C}$ interaction modelled by the Stillinger-Weber potential was fitted to reproduce the carbon Frenkel pair formation energy and the carbon interstitial activation energy. More details will be shown in the following paragraph.

\section{Point defects in uranium mono-carbide}

Point defect behaviour in UC has been extensively studied in the seventies, and Matzke [3] highlighted in his review how complex the microscopic mechanisms are. Experimental results obtained until now on point defect formation energies in UC are controversial. For example, the uranium vacancy formation energy has been evaluated to be between $1.7 \mathrm{eV}$ and $3.7 \mathrm{eV}$, while the uranium interstitial migration energies are determined to range from 4.6 to $7.5 \mathrm{eV}$, depending on the experimental techniques used (see [3] for all the data sets). These important differences may be due to the fact that samples are not stoichiometric and contain some impurities.

Using the present potentials, we have calculated the point defect formation energies and their activation energies for migration using a super-cell including $8 \times 8 \times 8$ unit cells, which involves 216 atoms. The Frenkel pair formation energies have been calculated using the standard following equation, which is the difference between two cells, one cell containing one vacancy and one interstitial and other being the perfect cell:

$E_{\mathrm{f}}^{\mathrm{PF}}(\mathrm{C})=E\left(\mathrm{U}_{k} \mathrm{C}_{k+1}\right)+E\left(\mathrm{U}_{k} \mathrm{C}_{k-1}\right)-2 k E(\mathrm{UC})$

where $k$ is the number of atoms in the simulation cell.

The experimental Frenkel pair formation energy for carbon is $2.24 \mathrm{eV}$ [4]. This value has been used to adjust the parameter A in the Stillinger-Weber potential. The calculated formation energy resulting from the fit is equal to $1.5 \mathrm{eV}$. This is slightly lower than the experimental value (see Table 3). In comparison, the calculated value for the uranium Frenkel pair is very high $6.8 \mathrm{eV}$. The vacancy formation energies for stoichiometric UC can be estimated [1] as $E_{\mathrm{f}}\left(V_{\mathrm{U}}\right)=E_{\mathrm{f}}(F P U) / 2=3.4 \mathrm{eV}$ for the $\mathrm{U}$ vacancy and $E_{\mathrm{f}}\left(V_{\mathrm{C}}\right)=0.75 \mathrm{eV}$ for the $\mathrm{C}$ vacancy. These values are very close to the experimental values [3] which are 3.7 and $1.1 \mathrm{eV}$, respectively. This confirms that the present potential can describe structural properties for perfect UC and

Table 3

Calculated formation energies and activation energies for migration for carbon and uranium in UC

\begin{tabular}{lllll}
\hline$(\mathrm{eV})$ & $E_{\mathrm{f}}($ Frenkel $)$ & $E_{\mathrm{f}}(\mathrm{AS})$ & $E_{\mathrm{mig}}$ (interstitial) & $E_{\mathrm{mig}}$ (vacancy) \\
\hline Uranium & 6.8 & 1.43 & 0.9 & 2.2 \\
Carbon & $1.5(2.24)$ & & 1.8 & 4.8 \\
\hline
\end{tabular}

As sets for anti-site. Formation energy for carbon Frenkel pair (in italic) has been evaluated from U-C phase diagram by Jeanne [4]. also point defects. Structural considerations $[1,3]$ confirm that carbon dimmers, $\mathrm{C}-\mathrm{C}$, are present for over-stoichiometry $\mathrm{UC}_{1+x}$ rather than uranium vacancies, which is consistent with the calculated formation energies. The $\mathrm{C}-\mathrm{C}$ dimmer stabilizes in a 110 plane as observed in $\mathrm{UC}_{2}$ [3], with a distance between carbon atoms of $1.13 \AA$. This value is shorter than the value of $1.3 \AA$ measured in $\mathrm{UC}_{2}$ [3].

The anti-site formation energy is rather low, $1.4 \mathrm{eV}$, compare to the carbon Frenkel pair formation energy. Following Catlow [1], it will be considered as an alternative path for uranium interstitial migration. Notice that the activation energy for carbon vacancy migration $(4.8 \mathrm{eV})$ is close to what was determined by $\mathrm{Li}$ et al. [13] for $\mathrm{ZrC}$ $(4.9 \mathrm{eV})$. This value is higher than the interstitial migration energy, unlike what is known in $\mathrm{UO}_{2}$.

Activation energies for migration of interstitials and vacancies have been obtained using an eigen-vectors following method that checks the nature of the eigen-values of the energy second derivatives matrix [10]. Results are quoted on Table 3. Such values enter the diffusion coefficient, which is

$D=D_{0} \exp \left(-\left(\Delta E_{\mathrm{f}}+\Delta E_{\mathrm{m}}\right) / k_{\mathrm{B}} T\right)$.

The pre-factor $D_{0}$ and the entropy of formation, $\Delta S_{\mathrm{f}}$, and of migration, $\Delta S_{\mathrm{m}}$, will not be considered here, while the enthalpy $\Delta H$ of migration will be reduced to the internal energy $\Delta E$ only.

Considering first carbon migration, we can evaluate the migration energy as the sum of the vacancy (or interstitial) formation energy $E_{\mathrm{f}} / 2$ and the activation energy for migration $E_{\mathrm{mig}}$ in the stoichiometric composition. Of course, there is no need to create any interstitials for over-stoichiometric composition, contrary to the under-stoichiometric case if interstitial migration is considered. Activation energies for migration are lower (see Table 3) for interstitials than for vacancies. Consequently, carbon migration is caused by interstitial mechanisms. This is confirmed when comparing the calculated values (see Table 4) with the selected ones by Catlow [1]. The comparison is less straightforward when values selected by Matzke [14] are considered, and this is very true for over-stoichiometric composition.

Since under-stoichiometric UC results in carbon vacancies rather than uranium interstitials, uranium migration in this composition does occur through the carbon vacancies. The calculated activation energy is $6.6 \mathrm{eV}$, close to experimental value $(6.7 \mathrm{eV}$, see [15]). The mechanism is identical for stoichiometric composition, but the formation energy for the carbon vacancy has to be added. The resulting value is close to the experimental one, selected by Catlow [1], showing the same trend. While these calculations confirm the hypothesis proposed by Catlow [1] that the migrations occur through the carbon vacancy, they are still in the range of values recommended by Matzke [14], which makes us rather confident in the high quality of the present potentials. 
Table 4

Migration energies of uranium and carbon in UC as a function of the stoichiometry calculated using values reported on Table 3

\begin{tabular}{|c|c|c|c|}
\hline \multirow{2}{*}{$\begin{array}{l}\mathrm{UC}_{1+x} \\
\text { Migration }\end{array}$} & \multicolumn{3}{|l|}{ Migration energies $(\mathrm{eV})$} \\
\hline & $x<0$ & $x=0$ & $x>0$ \\
\hline \multicolumn{4}{|l|}{ Carbon } \\
\hline Vacancy & $E_{\text {mig }}=4.8$ & & \\
\hline Interstitial & $E_{\mathrm{f}}(\mathrm{PF} \mathrm{C})+E_{\mathrm{mig}}(\mathrm{C})=3.4$ & $E_{\mathrm{f}}(\mathrm{PF} \mathrm{C}) / 2+E_{\mathrm{mig}}(\mathrm{C})=2.6$ & $E_{\text {mig }}(\mathrm{C})=1.8$ \\
\hline Exp. Catlow [1] & 3.9 & 2.8 & $1.9-2.4$ \\
\hline Exp. Matsui [23] & 4.0 & 3.7 & 4.0 \\
\hline \multicolumn{4}{|l|}{ Uranium } \\
\hline Through $V_{\mathrm{C}}$ & $E_{\mathrm{mig}}=6.6$ & $E_{\mathrm{f}}(\mathrm{PF} \mathrm{C}) / 2+E_{\mathrm{mig}}(\mathrm{U})=7.4$ & \\
\hline Exp. Catlow [1] & 6.7 & 7.6 & \\
\hline
\end{tabular}

Table 5

Insertion energies of $\mathrm{He}, \mathrm{Kr}$ and $\mathrm{Xe}$ in $\mathrm{UC}$

\begin{tabular}{lcccl}
\hline Incorporation & $V_{\mathrm{C}}$ & $V_{\mathrm{U}}$ & Interstitial & Interstitial migration \\
\hline $\mathrm{He}$ & 0.6 & 0.1 & 2.3 & 0.7 \\
$\mathrm{Kr}$ & 8.7 & 2.1 & 9.3 & 0.6 \\
$\mathrm{Xe}$ & 10.5 & 4.0 & 10.8 & 0.5
\end{tabular}

\section{Rare gas incorporation and migration in uranium mono- carbide}

Helium, Krypton and Xenon insertions and migrations have been simulated using empirical potentials available in the literature [2]. Within these potentials, the rare gascarbon and uranium interactions are described using the Buckingham potentials only.

Insertion energies have been calculated for a single rare gas atom in the interstitial site, as well as in uranium and carbon vacancies. Results quoted in Table 5 clearly show that rare gases are more stable inside the uranium vacancy, rather than in carbon vacancy or in interstitial positions. The values for helium are close to what is seen in silicon carbide, where the insertion energy is higher in interstitial sites than in the vacancy site [16]. Conversely, the trend is reversed in $\mathrm{UO}_{2}$, where the interstitial incorporation energy is calculated to be lower than the vacancy energy [16].

Activation energies for migration have also been evaluated and quoted on Table 5. The activation energies for interstitial migration have values ranging from 0.5 to $0.7 \mathrm{eV}$. Notice that the last values compared well with the experimental ones at $0.5 \mathrm{eV}[3]$.

\section{Conclusion}

We have adjusted an EAM potential for the uranium mono-carbide. The properties calculated at the equilibrium show very good agreement with available experimental data. In particular, the energy differences between the B1 and B2/B3 structures are well reproduced. Point defects formation energies have also been evaluated within this EAM potential.

Results obtained show that the carbon Frenkel pair has a lower formation energy than the uranium ones. This result is in agreement with experimental evidence, and con- firms that under-stoichiometric uranium carbide contains carbon vacancies rather than uranium interstitials.

Activation energies for migration have also been evaluated. The analysis of the different microscopic paths seems to confirm the hypothesis assumed by Catlow [1]. Carbon migrates through an interstitial path while the uranium migration is possible through a carbon vacancy. Nervetheless, the calculated values for migration energies are in the range recommended by Matzke [3].

Incorporation and migration energies have been calculated for $\mathrm{He}, \mathrm{Kr}$ and $\mathrm{Xe}$, in order to check the relevancy of the inter-atomic potentials available in literature [2]. Values obtained show behaviours close to what was obtained in $\mathrm{SiC}$ [16] rather than in $\mathrm{UO}_{2}$ [17]. Nonetheless, the activation energy for $\mathrm{Xe}$ is in very good agreement with the experimental value.

In summary, the present EAM potentials and interatomic potentials for $\mathrm{He}, \mathrm{Kr}$ and $\mathrm{Xe}$ are suitable for molecular dynamic simulation of rare gas behaviour in uranium mono-carbide.

\section{References}

[1] C.R.A. Catlow, J. Nucl. Mater. 60 (1976) 151.

[2] H.H. Andersen, P. Sigmund, Nucl. Instr. and Meth. B 38 (1965) 238.

[3] Hj. Matzke, Science of advanced LMFBR fuels, Solid State Physics, Chemistry and Technology of Carbides, Nitrides and Carbonitrides of Uranium and Plutonium, North-Holland, 1986.

[4] F. Jeanne, Contribution à l'étude thermodynamique du système Uranium-Carbone Thèse de l'Université Scientifique et Médicale de Grenoble (1972).

[5] H.H. Hill, Plutonium and other Actinides, Vol. 17, American Institute of Mining, Metallurgical and Petroleum Engineers, New York, 1970, p. 2.

[6] M. Kurihara, M. Hirata, R. Sekine, J. Onoe, H. Nakamatsu, T. Mukoyam, H. Adachi, J. Alloys. Compd. 283 (1999) 128.

[7] E. Yamamoto, Y. Haga, Y. Inada, M. Murakawa, Y. Onuki, T. Maehira, A. Hasegawa, J. Phys. Soc. Jpn. 68 (1999) 3953.

[8] M. Eckle, R. Eloirdi, T. Gouder, M. Colarieti Tosti, F. Wastin, J. Rebizant, J. Nucl. Mater. 334 (2004) 1.

[9] A.S. Barnard, S.P. Russo, Mol. Phys. 100 (2002) 1517.

[10] J.D. Gale, A.L. Rohl, Mol. Simulat. 29 (2003) 291.

[11] A. Padel, Ch. de Novion, J. Nucl. Mater. 33 (1969) 40.

[12] M. Freyss, private communication.

[13] J. Li, D. Liao, S. Yip, R. Najafabadi, L. Ecker, J. Appl. Phys. 93 (2003) 9072 .

[14] Hj. Matzke, Solid State Ionics 12 (1984) 25. 
[15] J.R. Matthews, UKAEA Report, AERE-M 2643 (1974).

[16] R.M. Van Ginhoven, A. Chartier, C. Meis, W.J. Weber, L.R. Corrales, J. Nucl. Mater. 348 (2006) 51.

[17] M. Freyss, N. Vergnet, T. Petit, J. Nucl. Mater. 352 (2006) 144.

[18] J.A. Jackman, T.M. Holden, W.J.L. Buyers, P.deV. DuPlessis, O. Vogt, J. Benossar, Phys. Rev. B 33 (1986) 7144.

[19] J.L. Roubort, J. Nucl. Mater. 40 (1971) 17.
[20] F.L. Oetting, J.D. Navratil, E.K. Storms, J. Nucl. Mater. 45 (1972/ 73) 271.

[21] A. Pattoret, J. Drowart, S. Smoes, Bull. Soc. Fran. Céram. 77 (1967) 75.

[22] C.W. Tucker, Acta Crysta. 4 (1951) 425.

[23] H. Matsui, Hj. Matzke, J. Nucl. Mater. 88 (1980) 317. 